\title{
The effect of irrelevant surround on speeded visual discriminations varying in complexity
}

\author{
WAYNE P. SILVERMAN* \\ Institute for Basic Research in Mental Retardation, 1050 Forest Hill Road, Staten Island, New York 10314
}

\begin{abstract}
To measure the effect of varying stimulus material on visual matching, a three-factor experimental design was employed, with "same"-"different" RT as the main dependent variable. Pairs of sequences of meaningless shapes served as stimuli, varying in discriminability (high or low), complexity (sequence lengths of 1, 2, 5, or 8 shapes), and level of pair difference (identical sequences or sequences with one pair differing). All independent variables significantly affected RT, with (a) high-discriminability stimuli being reacted to faster than low, (b) RT increasing with sequence pair length, and (c) "same"-response RTs interacting with "different"-response RTs. A significant triple-order interaction component implied that, while a single-process self-terminating feature testing model could accommodate data from the low-discriminability condition, the high-discriminability data did not fit this model. The results are taken as support for a dual-process model to account for the data from "same" "different" RT tasks.
\end{abstract}

Reaction time (RT) studies investigating the nature of processing involved in physical discriminations between a pair of visual stimuli have yielded results which, by and large, fail to conform to any of the theoretical single-process feature testing models of information processing. (cf. Nickerson, 1972). The main reason for the incompatibility of results and theoretical models is the finding that RTs for the "different" stimuli fit into either a parallel or serial, self-terminating model, while the RTs for the "same" stimuli fail to fit these models. The empirical result which best illustrates this point is the finding that $\mathrm{RT}_{\text {same }}$ was sometimes less than $\mathrm{RT}_{\mathrm{d} \text { iff }}$, although "same" pairs always required exhaustive processing, while the processing of "different" pairs could be terminated when any relevant difference was detected. This incongruity between results and theory led Bamber (1969) to propose a dual-process model to account for the data, with a self-terminating process to account for "different" responses, and a template matching process (Neisser, 1967), called the "identity reporter," to account for "same" decisions.

Other two-process models have been proposed (cf. Beller, 1970; Krueger, 1973; Silverman, 1973; Tversky, 1969) to account for the "same"."different" RT data. The potential value of these models as better predictors of task performance than the single-process models (tempered with considerations of experimental artifact) rests on the issue of establishing qualitative differences in the RT functions describing the "same" and "different" judgments. Krueger (1970) has investigated effects of irrelevant information on the $\mathrm{RT}_{\text {same }}$ $\mathrm{RT}_{\text {diff }}$ contrast, and found that, when letter pairs were surrounded by bracketing lines, the "height of

* Send reprint requests to: Wayne Silverman, Department of Psychology. New York State Institute for Research in Mental Retardation, 1050 Forest Hill Road, Staten Island, New York 10314. bracketing lines had a greater effect on 'different' than 'same' judgments [p. 324]." Further investigation (Krueger, 1973) showed that the nature of the surround (whether symmetrical or asymmetrical) had a differential effect on $\mathrm{RT}_{\text {same }}$ and $\mathrm{RT}_{\mathrm{diff}}$; if the surround was the same for both stimulus elements (symmetrical), the "different" responses were slowed more than the "same" judgments, while the "different" responses tended to become faster with the addition of surround material that was different (asymmetrical) for the two stimulus letters. Krueger hypothesized that these results might be due to the processing of the surround material and the letter pair as a global stimulus. This would result in a lowering of the percentage of features which differed between the two pair elements when symmetrical material was added, making a "difference" harder to detect. In contrast, if the surround differed for the pair members (asymmetrical), a correct "same" judgment required the inhibition of the "different" response when the surround difference was detected, while the correct "different" response might have been "primed." A drop in $\mathrm{RT}_{\text {diff }}$ relative to $\mathrm{RT}_{\text {same }}$ and an increase in "false different" responses seem to support this argument. Therefore, a single-process model could account for these data if the assumption is made that irrelevant surround features are not completely filtered (cf. Broadbent, 1971).

Hawkins and Shigley (1972) have further evidence of a differential effect of irrelevant information on the "same" vs "different" decision processes when pairs of three-dimensional shapes served as stimuli, but again the finding shows that incompatibility of the irrelevant information with the appropriate response predicts results, and inefficient filtering of the irrelevant dimension(s) could account for the observed differences.

Silverman (1973) demonstrated that the $\mathrm{RT}_{\text {same }}$ data deviated from a single-process self-terminating model 


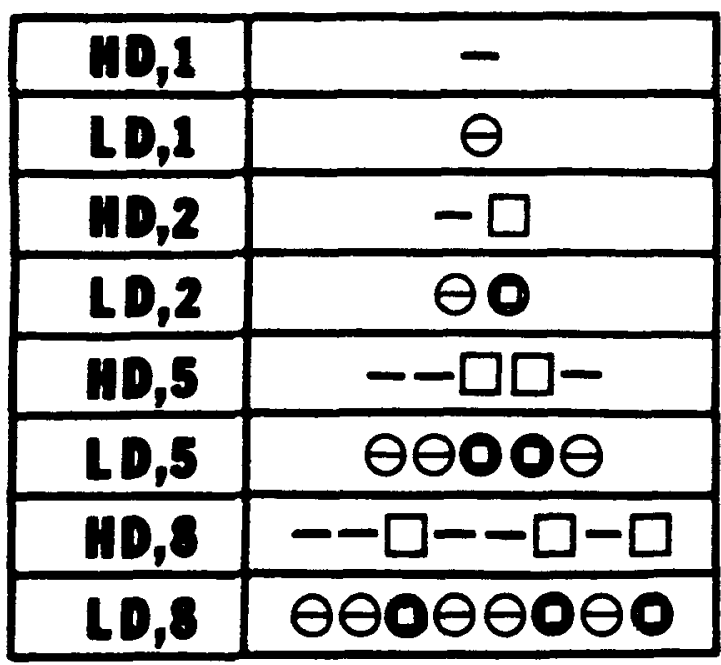

Fig. 1. Examples of shape sequences of the various lengths (1, 2,5 , or 8 shapes) and diccriminability [high (HD) or low (LD)] used to construct the stimuli.

with relatively simple stimuli, but fit the model with complex stimuli, and suggested that any "identity reporter function" was the result of some limited-capacity processing subsystem. The results implied that this system's capacity was a function of stimulus discriminability and size measured in "chunks" (Miller, 1956). The manipulation of discriminability was, however, subjective, and the conclusion that this was a crucial factor was tentative.

This "paper describes a study designed to test the effect of varying stimulus discriminability and length on the "same"."different" RT task, and to verify the previous conclusion that stimulus discriminability affects the "identity reporter function." Discriminability is manipulated by adding identical irrelevant information to all stimulus elements, and it is predicted that the addition of irrelevant information will slow both responses. Because there is a resultant decrease in stimulus discriminability, the "identity reporter function" capacity should also be lowered and the "same" judgment should be more severely influenced by the presence of irrelevant information as stimulus length increases.

\section{METHOD}

\section{Design}

A three-factor design was used, with two responses ("same" vs "different"), two types of stimulus shapes, varying in discriminability (high or low), and four levels of sequence length (strings of $1,2,5$, or 8 shapes being matched). All factors were within-S variables.

\section{Subjects and Apparatus}

Eight adult males served as Ss. All were familiar with the experimental procedure, and all but two were highly practiced, having participated in five previous sessions with stimuli similar to those employed in this experiment. ${ }^{1}$ All $\mathrm{Ss}$ had normal or corrected to normal vision.
The apparatus consisted of two Kodak Ectographic projectors, each fitted with a Lafayette Model 43011 (TAP-E) shutter mechanism. One projector controlled a warning stimulus, while the other presented the test stimulus. Stimuli were rear-projected on a frosted glass screen, mounted on a table in front of $S$, with time durations controlled by a Lafayette $1451 \mathrm{~A}$ eight-bank timer.

$S$ viewed the stimuli from a distance of approximately $60 \mathrm{~cm}$ while seated at a table. On the table, in addition to the screen, were two response keys, one for each hand, mounted $11.3 \mathrm{~cm}$ apart, the depression of which triggered a Hewlett-Packard 5223 L-5050A counter-recorder combination, which registered S's RT (to the nearest millisecond) and response.

\section{Stimuli}

Two strings of shapes, projected one above the other, served as the stimuli. The specific shapes used were: in one condition (high discriminability), a square or a horizontal line equal in length to one side of the square; and, in the second condition (low discriminability), a square and a horizontal line inscribed in a circle. All lines were $0.8 \mathrm{~mm}$ thick when projected, and each shape measured $13.5 \mathrm{~mm}$ long. Stimuli were viewed as bright on a dark background. The shapes within each string were separated by $3.1 \mathrm{~mm}$, and the two strings were separated by $7.9 \mathrm{~mm}$. Each string contained $1,2,5$, or 8 shapes, randomly ordered, and pairings were always between two sequences of equal length. Figure 1 illustrates examples of the stimulus types.

Two random orders were obtained for each sequence length in order to control for repetition effects, as there were only two alternatives for the Length 1 sequences. "Same" pairings consisted of five examples of each of the two sequences for each length paired with itself. "Different" pairings were constructed by changing one shape in the sequence, whose position varied, and matching it with the original sequence so that the pairing differed in only one position. There were a total of 10 "same" stimuli and 10 "different" stimuli for each sequence length in both the high-discriminability (HD) and low-discriminability (LD) conditions, to yield a total of 160 experimental trials.

Stimuli were grouped by discriminability into two blocks of 80 slides. Stimuli within each block were randomized in blocks of 16 slides (two "sames" and two "differents" for each sequence length), the only constraint being that not more than five consecu tive trials required a similar response.

\section{Procedure}

All Ss participated in one experimental session, lasting approximately $30 \mathrm{~min}$, during which all stimuli were presented. Ss were seated in a lighted room, and instructions describing the exact nature of the procedure were given; both speed and accuracy were stressed. One-half the $S$ s were instructed to respond "same" with the left hand, and the remainder were instructed to signal "same" with the right hand. Further, the order of block presentation was counterbalanced, so half the Ss responding "same" with either hand viewed the HD block before the LD block. The other Ss had the block order reversed.

A stimulus trial consisted of: (a) the projection of a red dot (as a warning stimulus) for $1 \mathrm{sec}$ onto the screen at the center of where the test stimulus was to appear; (b) the simultaneous offset of the warning stimulus and onset of the test stimulus, which remained visible until $S$ responded by pushing one of the response buttons; and (c) a variable intertrial interval of approximately $1 \mathrm{sec}$. No feedback was given between trials. There was a rest of several minutes between the two blocks of trials while $\mathrm{E}$ changed the slide tray.

Before presenting the test trials, S was given 20 warm-up trials on slides consisting of arrows pointing to either the right or left. $S$ was instructed to push the button to which the arrow pointed as quickly as possible; the purpose of this warm-up was to familiarize $S$ with his surroundings, the pace of the experimental trials, and the required motor responses. 


\section{RESULTS}

Median RTs were calculated for each S using the correct responses for each condition. These data were analyzed by a three-way within-Ss analysis of variance. The RT data are given in Table 1 and graphed in Fig. 2. Each value represents the mean of the individual S's median RTs for that condition.

Stimulus discriminability was a significant factor $[F(1,7)=67.8, p<.01]$, as was response $[F(1,7)=$ $10.8, \mathrm{p}<.05]$ and stimulus length $[\mathrm{F}(3,21)=66.4$, $\mathrm{p}<.01]$. Orthogonal breakdown of the length main effect showed that: (a) Length 1 and 2 stimuli did not differ significantly $[F(1,21)=2.4, p>.1]$; (b) Length 5 stimuli were slower than Length 1 and 2 stimuli combined $[F(1,21)=25.9, p<.01]$; and (c) Length 8 stimuli were slower than the shorter strings $[F(1,21)=$ $171.0, \mathrm{p}<.01]$.

All second-order interactions were significant. The Stimulus Discriminability by Response interaction showed that $\mathbf{R T}_{\text {same }}$ increased, overall, more than $\mathrm{RT}_{\text {diff }}$ with decreasing discriminability $[\mathrm{F}(1,7)=23.8$, $p<.01]$. The Response by Length interaction also showed that $\mathrm{RT}_{\text {same }}$ increased faster than $\mathrm{RT}_{\text {diff }}$ as stimulus length increased $[\mathrm{F}(3,21)=12.8, \mathrm{p}<.01]$, and the Stimulus Discriminability by Length interaction implied that the effect of the irrelevant surround was greater for the longer stimuli $[F(3,21)=18.4, p<.01]$.

The overall triple-order interaction was insignificant $[F(3,21)=2.1, \mathrm{p}>.1]$, but an orthogonal breakdown into trend components showed that the Linear by Linear by Linear interaction was significant $[F(1,21)=5.1$, $\mathrm{p}<.05]$, indicating that the differences in RT response function slopes were greater for the LD group than for the HD stimuli as sequence length increased.

Further analysis of the HD condition showed that the two response functions interacted with stimulus length $[F(3,21)=3.8, p<.05]$. Breakdown of this interaction showed that, for Stimulus Lengths 1,2, and 5 combined,

Table 1

Mean RTs (Milliseconds) and Percent Errors (in Parentheses) for the Various Stimulus Conditions

\begin{tabular}{|c|c|c|c|c|c|}
\hline & \multicolumn{2}{|r|}{ Stimulus } & \multicolumn{3}{|c|}{ Sequence Length } \\
\hline & 1 & 2 & 5 & 8 & Mean \\
\hline \multicolumn{6}{|c|}{ High Discriminability } \\
\hline Same & $\begin{array}{l}547.4 \\
(0)\end{array}$ & $\begin{array}{l}599.4 \\
(3.8)\end{array}$ & $\begin{array}{r}656.4 \\
(2.5)\end{array}$ & $\begin{array}{l}945.9 \\
(\quad 2.5)\end{array}$ & $\begin{array}{l}687.3 \\
(2.2)\end{array}$ \\
\hline Diff & $\begin{array}{l}612.1 \\
(12.5)\end{array}$ & $\begin{array}{l}572.7 \\
(3.8)\end{array}$ & $\begin{array}{r}683.7 \\
(5.0)\end{array}$ & $\begin{array}{l}884.5 \\
(7.5)\end{array}$ & $\begin{array}{l}688.2 \\
(7.2)\end{array}$ \\
\hline Mean & $\begin{array}{l}579.8 \\
(6.2)\end{array}$ & $\begin{array}{l}586.5 \\
(3.8)\end{array}$ & $\begin{array}{r}670.0 \\
(3.8)\end{array}$ & $\begin{array}{l}915.2 \\
(5.0)\end{array}$ & $\begin{array}{r}687.8 \\
(4.7)\end{array}$ \\
\hline \multicolumn{6}{|c|}{ Low Discriminability } \\
\hline Same & $\begin{array}{l}604.6 \\
(5.0)\end{array}$ & $\begin{array}{l}801.1 \\
(5.0)\end{array}$ & $\begin{array}{r}1068.2 \\
(10.0)\end{array}$ & $\begin{array}{r}1521.4 \\
(2.5)\end{array}$ & $\begin{array}{r}998.8 \\
(5.6)\end{array}$ \\
\hline Diff & $\begin{array}{r}651.2 \\
(3.8)\end{array}$ & $\begin{array}{l}708.2 \\
(11.2)\end{array}$ & $\begin{array}{r}898.4 \\
(15.0)\end{array}$ & $\begin{array}{r}1288.9 \\
(12.5)\end{array}$ & $\begin{array}{r}886.7 \\
(10.6)\end{array}$ \\
\hline Mean & $\begin{array}{r}627.9 \\
(4.4)\end{array}$ & $\begin{array}{r}754.6 \\
(8.1)\end{array}$ & $\begin{array}{r}983.3 \\
(12.5)\end{array}$ & $\begin{array}{r}1405.2 \\
(7.5)\end{array}$ & $\begin{array}{r}942.8 \\
(8.1) \\
\end{array}$ \\
\hline
\end{tabular}

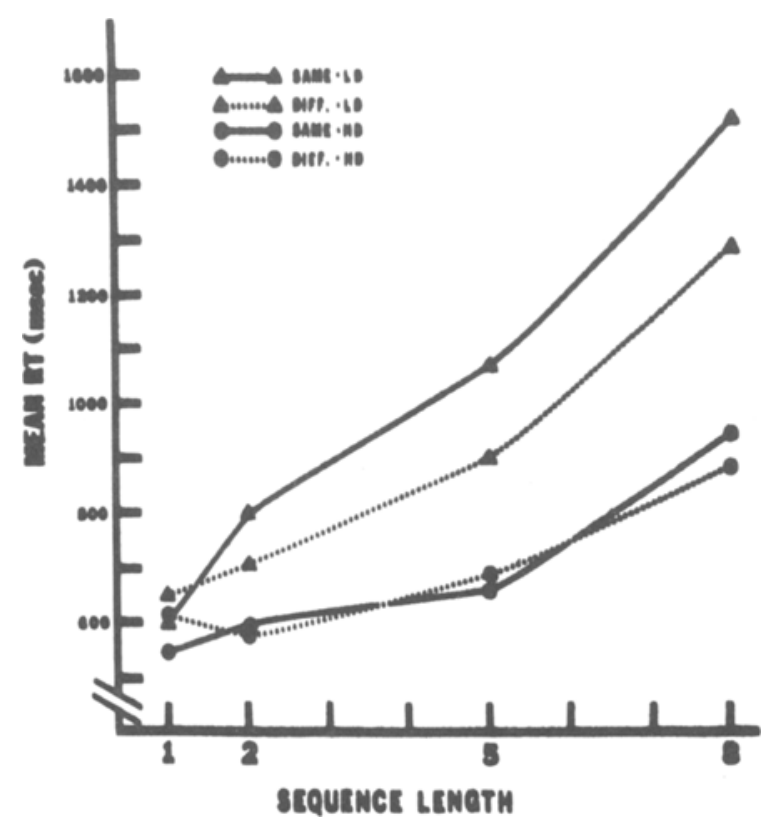

Fig. 2. Mean correct reaction times (milliseconds) for the several stimulus conditions.

$\mathrm{RT}_{\text {same }}<\mathrm{RT}_{\text {diff }}$, while for Stimulus Length 8, $\mathrm{RT}_{\text {diff }}$ $<\mathrm{RT}_{\text {same }}[\mathrm{F}(1,21)=6.3, \mathrm{p}<.05]$. For the $\mathrm{LD}$ condition, a significant Response by Length interaction was due to $\mathrm{RT}_{\text {same }}<\mathrm{RT}_{\text {diff }}$ for the Length 1 stimuli and $\mathrm{RT}_{\text {diff }}<\mathrm{RT}_{\text {same }}$ for longer pairings $[\mathrm{F}(1,21)=$ $16.8, p<.01]$.

The consistency of the data across Ss could not be checked by analysis of variance, as there was only one median for each $\mathrm{S}$ within each cell of the experimental design. However, inspection of the four response functions (as in Fig. 2) for each $S$ showed a fairly constant relationship. For the LD condition, six of eight Ss were faster to respond "same" than "different" for the Length 1 stimuli. For all of the longer stimuli, $\mathrm{RT}_{\text {sam e }}$ was less than $\mathrm{RT}_{\text {diff }}$ on only two data points, each occurring in a different $\mathrm{S}$. For the HD condition, there is greater overlap of the two response functions, but at least six of eight Ss showed $\mathrm{RT}_{\text {same }}<\mathrm{RT}_{\text {diff }}$ for Stimulus Lengths 1 and 5 and $\mathrm{RT}_{\mathrm{diff}}<\mathrm{RT}_{\text {same }}$ for Stimulus Length 8 . There was no ordinal difference between the two responses for the Length 2 stimuli.

The error rates (given in Table 1) showed further differences in the data from the HD and LD conditions. A three-way within-Ss analysis of variance showed that, in addition to a higher overall error rate for the "different" responses than for the "sames" $[F(1,7)=$ $5.9, p<.05]$, there was a significant triple-order interaction $[F(3,21)=3.7, p<.05]$. Inspection of the data showed that, for the LD group, error rates for the "different" stimulus pairs are greater than for "same" pairs for the longer stimulus sequences, while in the HD condition, the largest difference in error rates between the two responses is for the Length 1 sequence pairs. All other error rate differences were insignificant $(F<1.0)$. 
Table 2

The Expected Number of Stimulus Pairs Scanned in Order to Reach a Correct Response

\begin{tabular}{ccc}
\hline Digit String Length & Different & Sime \\
\hline 1 & 1 & 1 \\
2 & 1.5 & 2 \\
3 & 2 & 3 \\
4 & 2.5 & 4 \\
5 & 3 & 5 \\
6 & 3.5 & 6 \\
7 & 4 & 7 \\
8 & 4.5 & 8 \\
\hline
\end{tabular}

\section{DISCUSSION}

These results indicate that the processing in the "same"."different" RT task changes greatly as stimulus discriminability is varied. There is a change in the rate of the comparison process, reflected by the slope of the RT functions as stimulus length increases, which is slower for the less discriminable stimuli. In addition, for stimuli that are easily differentiated, the data imply that $\mathrm{RT}_{\text {same }}$ is less than $\mathrm{RT}_{\mathrm{diff}}$ for stimulus sequences of up to Length 5, while in the LD condition, $\mathrm{RT}_{\text {same }}$ is faster than $\mathrm{RT}_{\text {diff }}$ for only the Length I stimuli. |Figure I shows that the Length 2 "different" stimuli were faster than the "same" stimuli in the HD condition. This unpredicted result can be explained by considering the particular stimuli used in this condition. The two stimulus sequences selected by chance were "square, line" and "line, square." "Different" stimuli were, therefore, always composed of three of one shape and one of the other. Donderi and Zelnicker $(1969)$ showed that, when an array of highly discriminable shapes are composed of either all the same members or all the same members but one, $\mathrm{RT}_{\text {diff }}<\mathrm{RT}_{\text {same, }}$ and both are independent of the total number of shapes in the array. This particular data point may therefore be the result of a different information processing system.]

The difference in the relationship between the two response RT functions for the two levels of discriminability support the argument that different processing mechanisms are operating within these conditions. Table 2 gives the expected number of stimulus pairs processed in order to reach a correct decision for the two responses with stimulus sequence lengths of from one to eight items. If the two response judgments are the result of the same information processing scheme, which has been established as self-terminating for the "different" stimuli (cf. Nickerson, 1972), the slope of the "same" response function should be approximalely twice that of the "different" response function as stimulus length increases.

Linear regression lines were calculated for the two response functions of each dixcriminability condition, and it was found that the slopes of these lines (Fig. 2) were similar in the IID condition $(5.3 \mathrm{msec} / \mathrm{stimulus} \mathrm{pair}$ for "same," and $41 \mathrm{msec} / \mathrm{stimulus}$ pair for "different"), while for the LD condition, the "same" slope was greater than that of the "different" slope (123 $\mathrm{msec}$ vs $89 \mathrm{msec} / \mathrm{stimulus}$ pair, respectively). (The linear correlations for thesc four lines were equal to or greater than 0.943.)

Figure 2 shows that, for Sequence Length 8 stimuli, the LD "different" response seems longer than a linear increase in RT would have predicted. It is possible that, as processing of the longer strings progressed and a "difference" was not detected, the "same" response was being primed by $\mathbf{S}$ (cf. Grill, 1971). If this was the case, the "different" response would first require an inhibition of the "same" response, which would increase RT; the large difference in error rates between the "same" and "different" stimuli in this condition support this notion. If the Length 8 "different" data are omitted and a new regression line is calculated, the slope of this function (62.2 msec/stimulus pair) falls 10 almost exactly half of the "same" response function, showing that the LD data can be accommodated by a self-terminating model with allowance for experimental artifact (i.e., bias favoring a "same" response). However, artifact does not seem to be able to account for differences in the relationships of the two responses between the two discriminability conditions.

Lockhead (1972) has proposed a dual-process model which might handle these data. Perhaps the HD condition was processed as a single "integral blob." In this case, HD stimuli would be processed in a functionally exhaustive scheme, as "there is no requirement for independent decisions on the separate dimensions $\mid p .415]$." and the lack of overall difference between $\mathrm{RT}_{\text {same }}$ and $\mathrm{RT}_{\mathrm{diff}}$ is explained, as the number of comparisons for both judgments is the same for any given stimulus length. LD stimuli might be processed as "complex nonintegral stimuli," and these data would conform to a self-terminating model. Lockhead's model does not, however, seem to predict the Response by Stimulus Length interaction observed in the HD condition, nor does it account for previous findings ( $\mathrm{c} f$. Silverman, 1973) showing that, while $\mathrm{RT}_{\text {same }}$ is less

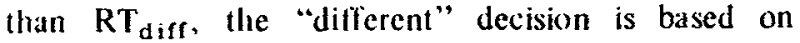
self-terminating processing.

The error data lend additional support to the notion that the processing is qualitatively different in the two discriminability conditions. The higher error rate for "different" than for "same" pairs shows that a possible speed-accuracy tradeoff was operating similarly for the longer length stimuli in the two dixcriminability conditions:therefore, it cannot account for the observed differences in the two sets of response function slopes.

In summary, the divergence of the "same" RT response function slope of the HII) condition from its expected value of approximately twice that of the "different" RT response function slope as stimulus length increases makes these data incompatible with a onc-process self-terminating model. These results 
support a dual-process model with some "identity reporter function" (Silverman, 1973) operating in addition to the self-terminating feature testing process. This "identity reporter function" was formulated as a limited-capacity system, and it was predicted that stimulus discriminability influenced its capacity. The fact that $\mathrm{RT}_{\text {same }}$ was less than $\mathrm{RT}_{\mathrm{diff}}$ for only the Length 1 stimuli in the LD condition, but in the HD condition $\mathrm{RT}_{\text {sam e }}$ was less than $\mathrm{RT}_{\text {diff }}$ for stimuli up to Length 5 , tends to confirm this prediction.

\section{REFERENCES}

Bamber, D. Reaction times and error rates for "same"_"different" judgments of multidimensional stimuli. Perception \& Psychophysics, 1969, 6, 169-174.

Beller, H. K. Parallel and serial stages in matching. Journal of Ex perimental Psychology, 1970, 84, 213-219.

Broadbent, D. Decision and stress. London: Academic Press, 1971.

Donderi, D., \& Zelnicker, D. Parallel processing in visual "same"."different" decisions Perception \& Psychophysics, $1969,5,197-200$.

Grill, $D$. Variables influencing the mode of processing of complex stimuli. Perception \& Psychophysics, 1971, 10, 51-57.

Hawkins. H., \& Shigley, R. H. Irrelevant information and processing mode in speeded discrimination. Journal of Experimental Psy chology, 1972, 96, 389-395.
Krueger, L. Effect of bracketing lines on speed of "same"s"different" judgment of two adjacent letters. Journal of Ex perimental Psychology, 1970, 84, 324-330.

Krueger, L. Effect of irrelevant surrounding material on speed of same-different judgment of two adjacent letters. Journal of Experimental Psychology, 1973, 88, 252-259.

Lockhead, G. R. Processing dimensional stimuli: A theoretical note. Psy chological Review, 1972, 79, 410-419.

Miller, G. The magical number seven plus or minus two: Some limits on our capacity for processing information. Psy chological Review, 1956, 63, 81-87.

Neisser, U, Cognitive psychology. New York: Appleton-Century-Crofts, 1967.

Nickerson, R. Binary classification reaction time: A review of some studies of human information-processing capabilities. Psychonomic Monograph Supplements, $1972,4,275-318$.

Silverman, $W$. The perception of identity in simultaneously presented complex visual displays. Memory \& Cognition, $1973,1,459-466$.

Tversky, B. Pictorial and verbal encoding in a short-term memory task. Perception \& Psychophysics, 1969, 6, 225-233.

\section{NOTE}

1. Eight Ss were required for complete counterbalancing, and only six practiced Ss were available. The data of the two unpracticed were within the range of RTs from other Ss.

(Received for publication August 27, 1973; revision received November 14, 1973.) 